\title{
Ekologinen luomusikala
}

\author{
Tapani Kivinen \\ MTT Maatalousteknologian tutkimus (Vakola) \\ Vakolantie 55 FIN-03400 VIHTI \\ tapani.kivinen@mtt.fi
}

\section{Johdanto}

Euroopan Unionin tasolla luonnonmukaisen eläintuotannon lakisääteisten vähimmäisvaatimusten valmistelutyö päättyi heinäkuussa 1999 kun luonnonmukaista tuotantoa koskevaa neuvoston asetusta (ETY) N:o 2092/1 täydennettiin käsittämään myös eläintuotanto. Kasvintuotannon tarkastuskeskus KTTK julkaisi kansalliset luonnonmukaisen eläintuotannon ohjeet elokuussa 2000. Maa- ja elintarviketalouden tutkimuskeskus on yhteistyössä Farma Maaseutukeskuksen, VTT:n, Teknillisen Korkeakoulun ja Luomuliitto ry:n kanssa kehittänyt edellä kuvattujen uusien tuotanto-ohjeiden mukaisen luomusikalamallin. Suunnitelmasta tullaan rakentamaan mallirakennus Tuomelan tilalle Hausjärvelle vuoden 2002 aikana.

Sianlihatuotannon rakenne on muutoksessa. Tavanomainen tuotanto hakee tehokkuutta yksikkökoon kasvattamisella. 1000 - 2000 -paikkaista lihasikalaa voidaan nykyään pitää normaalikokoisena, ja uudet suuret emakkosikalat ovat laajimmillaan 900 -paikkaisia. Luomusianlihan tuotannon filosofia ei perustu tuotantokustannusten minimointiin vaan laadun maksimointiin. Luomulihan tuotanto hakee markkinarakoa kuluttajista, jotka arvostavat eläinten luontaisten tarpeiden huomioon ottamista tuotantomenetelmissä. Luomusianlihan kysyntä on suurempaa kuin tuotanto. Luomusianlihan kulutus vuonna 2000 oli vain 0,7 \% kaikesta myydystä sianlihasta. Tuotannon alkuvaikeudet ovat johtuneet yhtäältä toimivien rakennusratkaisujen puutteesta ja toisaalta tukipolitiikan selkiytymättömyydestä. Luomusikalahankkeen tarkoituksena onkin ollut tuoda markkinoille tutkittu ja toimiva rakennusmalli, jonka avulla tuotantoympäristöt saadaan nopeasti aikaiseksi. Luomulihan markkinapotentiaali on suuri ja pienetkin lisäykset tuntuvat suurina muutoksina.

\section{Luomusikalan ekologiset ominaisuudet}

Luomusikala eroaa tavanomaisesta sikalarakennuksesta eläinten ulkoiluun vaadittujen alueiden ja väljemmän pinta-alavaatimuksen vuoksi. Tämän lisäksi luomusikalan eläinten käytettävissä olevasta lattiapinta-alasta yli $50 \%$ on oltava kiinteäpohjaista. Lisäksi rakennukselta edellytetään hygieenisyyttä, turvallisuutta ja valoisuutta. Luomuohjeet eivät tämän tarkemmin vaadi rakennukselta kestävän kehityksen mukaisia ympäristöllisiä ominaisuuksia. Tässä tutkimus- ja kehityshankkeessa myös itse rakennukselle haluttiin luoda ekologiset kriteerit, jotta rakennus olisi yhtä lailla luomuhenkinen kuin itse tuotantoprosessi ja lopputuotekin.

Rakennuksen ekologiset kriteerit kiteytettiin kolmeen osatekijään, joiden vaikutus ulottuu rakennuksen koko elinkaareen. Ensiksi rakennuksen toiminnallisen ratkaisun tulee olla niin yksinkertainen, että rakennus pystyy joustamaan erilaisiin maatalouden tuotantotilavaatimuksiin. Toiseksi rakennuksen energian käyttöä tulee minimoida. Tarkastelussa ovat mukana rakennuksen rakentamisaikaisen energian tarve ja matalan tuotantoenergian omaavat rakennusmateriaalit. Rakennuksen normaalia paremmalla lämpöeristyksellä tähdätään koko elinkaaren mittaisen energiakulutuksen minimointiin. Kolmanneksi rakennusmateriaaleiksi hyväksytään vain luonnolliset ja perinteiset materiaalit kuten puu sen eri muodoissaan, betoni, lasi ja teräspelti. Muovipohjaisten materiaalien käyttö pyritään rajaamaan minimiin. Materiaalit ovat myrkyttömiä ja niitä on helppo kierrättää ja turvallista loppusijoittaa tai polttaa. Edellä lueteltujen ekologisten kriteerien lisäksi rakennuksen julkisivuarkkitehtuuriin haluttiin panostaa, jotta luomusikalasta saadaan ympäristöstään positiivisesti erottuva tuotantorakennus. Laadukkaalla arkkitehtuurilla nostetaan luomutuotannon ja samalla koko maaseuturakentamisen imagoa. 


\section{Toiminnalliset pohjaratkaisut}

Tutkimushanke kehitti yhdistelmäsikalamalli 35 emakolle ja 168 lihasialle. Rakennuksen kokonaisala on $1131 \mathrm{~m}^{2}$. Lämpöeristetty ala on $1009 \mathrm{~m}^{2}$ (eläintilat, lastaustila ja toimisto) ja eristämätön ala $122 \mathrm{~m}^{2}$ (kuivikevarasto ja rehuvarasto). Rakennuksen pituus on 62,7 $\mathrm{m}$ ja leveys $16,2 \mathrm{~m}$. Karsinakoon perusmittana on 2,4 m leveys, joka toistuu säännöllisenä moduulina rakennuksen pituussuunnassa. Luomuohjeiden mukaan jokaisesta karsinasta on oma uloskäynti rakennuksen vieressä olevaan asfalttipäällysteiseen jaloittelutarhaan. Jaloittelun on oltava mahdollista ja vapaata toukokuusta lokakuun loppuun. Talvikuukausina sikoja ei tarvitse päästää ulos, mutta ne voidaan päästää viljelijän harkinnan mukaan. Ulkoilu ei ole pakollista imettäville emakoille, alle 10 -viikkoisille porsaille sekä loppulihotusvaiheessa oleville lihasioille. Edellä sanotusta huolimatta tämä luomusikalamalli antaa kaikille eläinryhmille tasavertaiset mahdollisuudet ulkoiluun fyysisestä tilasta tai ajankohdasta riippumatta.

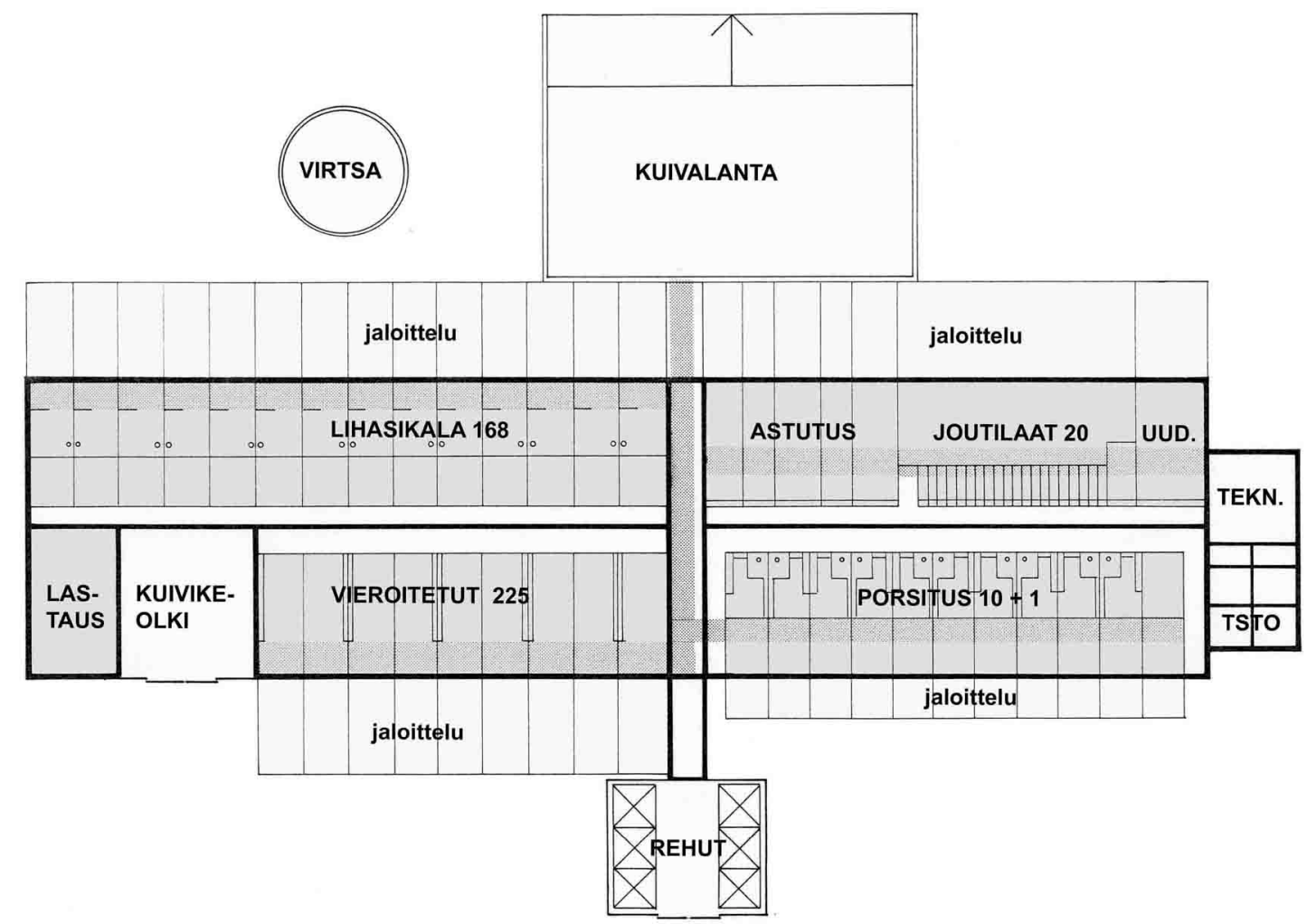

Kuva. 1: $\quad$ Yhdistelmäsikala 35 emakolle (oikea puoli) ja 168 lihasialle (vasen puoli), rakennuksen kokonaisala on $1131 \mathrm{~m}^{2}$.

Emakkojen tuotantokierto pyritään järjestämään 3 emakon ryhmäporsituksena. Tiineytysosastolla on kaksi karjukarsinaa, jotka on sijoitettu keskeisesti tiineytettävien karsinoihin nähden. Joutilaat ovat yhdessä ryhmässä runsaasti kuivitetussa täytepohjapihatossa, joka tyhjennetään traktorilla määrävälein. Porsitusosastolla on 10 karsinaa ja yksi sairaskarsina. Imetys kestää 50 päivää. Porsituskarsina jakautuu varsinaiseen imetyskarsinaan ja alkuvierotuskarsinaan. Alkuvierotuksessa porsaat siirretään omaan puoliskoonsa, josta on käynti ulkotarhaan. Emakko viedään sillä välin tiineytysosastolle, karsina pestään ja valmistellaan uutta emakkoa varten. Tämän jälkeen porsaat siirretään vieroitettujen osastolle, josta edelleen noin 30 - 40 -kiloisina lihasikalaan. Lihasikalan kaikki karsinat on mitoitettu 12 eläimelle ja suurimman kilomäärän neliövaatimuksen mukaan, joten pahnue viettää koko lihotusvaiheen samassa karsinassa.

Rakennukseen on tietoisesti valittu kuivalantajärjestelmä. Tämä mahdollistaa runsaan kuivikeoljen käytön, joka parantaa sikojen oleskeluviihtyvyyttä. Kuivalantajärjestelmä samalla minimoi märkien lattiapintojen määrää ja osaltaan auttaa sisäilman suhteellisten kosteuksien hallintaa. Samaan seikkaan tähtää kuivaruokintajärjestelmä. 
Yhdistelmäsikalamalli on tämän hetken tuotantotilanteessa ainoa toimiva luomusianlihan tuotantotapa. Rakennuksen toiminnallinen jousto mahdollistaa muutoksen pelkäksi emakkosikalaksi tai lihasikalaksi sitten kun luomuporsaiden välitysmarkkinat alkavat toimia. Pelkkänä emakkosikalana rakennukseen mahtuu 60 emakkoa; lihasikalana toimiessaan rakennukseen mahtuu 600 lihasikaa.

Toiminnallinen jousto merkitsee myös sitä, että rakennus voidaan tarvittaessa muuttaa lypsykarjarakennukseksi 55 lehmälle. Rakennus muuntuu myös perinteisestä maataloustuotannosta teollisuustyyppiseksi metalli- tai puutyöpajaksi, autokorjaamoksi tai tuotevarastoksi.

\section{Rakenneratkaisut}

Rakennuksen perusmuoto on yksinkertainen suorakulmio. Rakennus on jaettu käyttötavan mukaan neljään yhtä suureen osastoon. Rakennuksen laajennettavuus tapahtuu pituussuunnassa. Toimisto- ja rehutilat voidaan sijoittaa hyvin vapaasti riippuen rakennuksen sijainnista suhteessa tilakeskuksen muihin rakennuksiin ja liikennealueisiin.

Rakennuksen alapohja on kauttaaltaan lämpöeristetty ja paikalla valettua betonia. Seinät ovat 1,2 m korkeuteen lämpöeristettyä betoniharkkoa. Tästä korkeudesta ylöspäin rakennuksen runko, eristeet ja verhous on pääasiassa puuta. Vesikate on pinnoitettua teräsohutlevyä. Seinien sisä- ja ulkoverhouksena sekä antavana pystyrunkona käytetään tilan omasta metsästä saatavaa sahatavaraa. Kattotuolit ovat tehdasvalmisteisia naulalevypuuristikoita. Höyrysulkuna käytetään tervapaperia. Eristeenä seinissä käytetään puupohjaista selluvillaa ja katossa sahanpurua. Ikkunat ovat kaksinkertaisia lämpölasielementtejä, jotka kiinnitetään suoraan kantavaan puurunkoon.

Rakennuksen ulkoseinät ja myös keskiseinä ovat kantavia seinälinjoja. Tällöin lyhyt $8,1 \mathrm{~m}$ jänneväli mahdollistaa jopa itse tehtyjen kattoristikoiden käytön. Kantava keskiseinä voidaan jättää pois, jolloin 16,2 m jänneväli hoidetaan yhdellä tehdasvalmisteisella kattoristikolla.

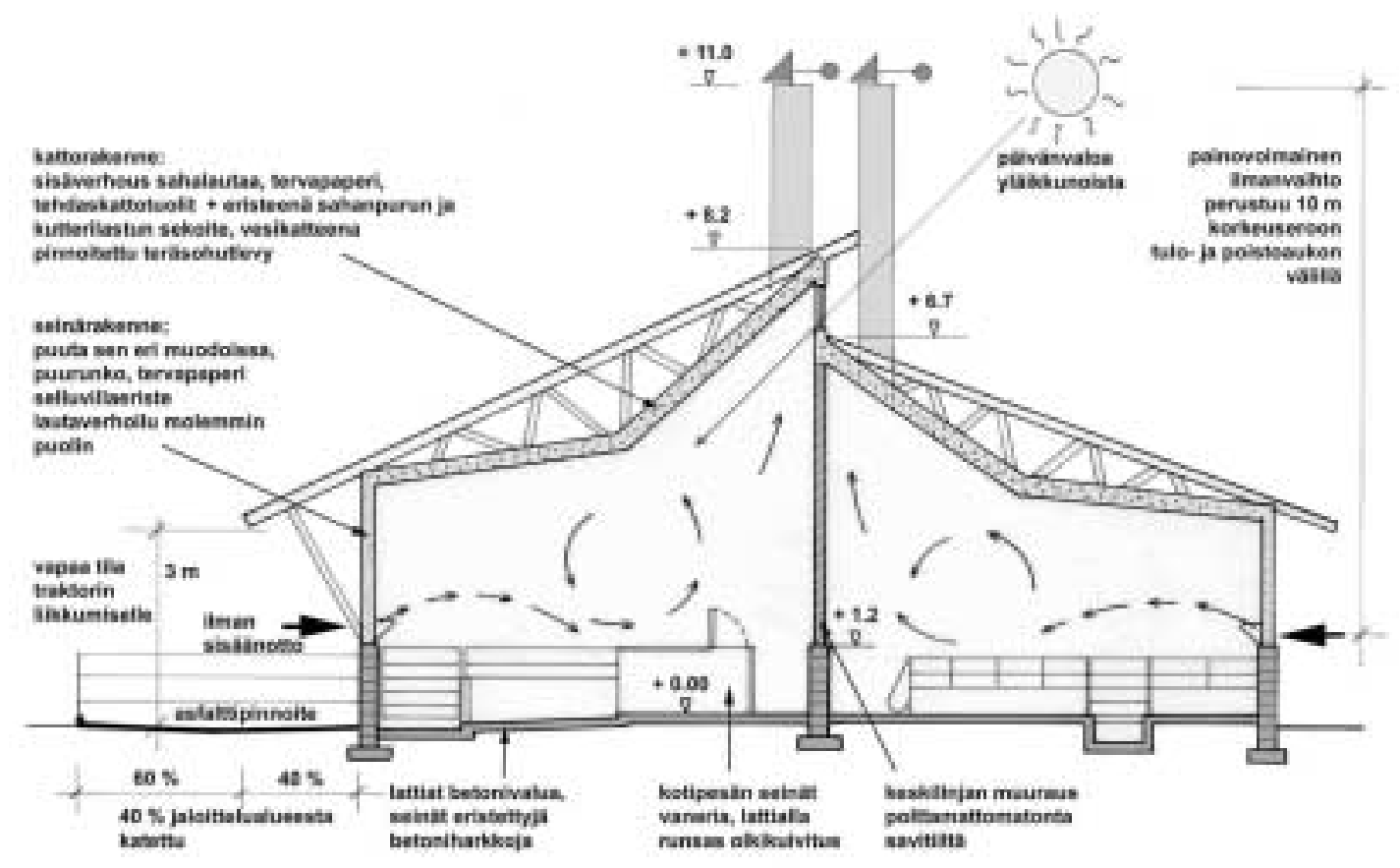

Kuva. 2: $\quad$ Luomusikalan leikkauspiirros. Ulko- ja keskiseinät ovat kantavia seinälinjoja. Rakennus voidaan toteuttaa myös perinteisellä harjakattoristikolla, jolloin runkokustannus tulee hieman halvemmaksi.

\section{Ekologiset materiaalit}

Rakennusmateriaalien ekologisuus perustuu matalaan tuotantoenergiaan (matala jalostusaste), myrkyttömyyteen ja kierrätettävyyteen. Materiaalit voidaan myös turvallisesti hävittää, polttaa tai muuten loppusijoittaa. Erityisesti seinien ja katon puupohjaisen kokonaisrakenteen toimivuudella tavoitellaan hyvää kosteusteknistä puskurointikapasiteettia, jolloin rakenne sietää korkeitakin suhteellisia kosteuksia vaurioitumatta. Keskilinjalla seinämateriaalina käytetään polttamatonta savitiiltä, jonka ominaisuuksiin 
kuuluu suhteellisen kosteuden suuri absorptio- ja luovutuskyky, jolloin se tasaa vuorokautisia kosteusvaihteluja. Lautaverhoiltujen sisäseinien käsittelynä käytetään kalkkisivelyä. Ulkopinnassa käytetään työmaalla keitettyä punamultamaalia. Puutavara hankitaan suurimmaksi osaksi viljelijän omista metsistä, jolloin materiaalin kuljetus- ja jalostusketju valmiiseen seinään asti jää lyhyeksi.

\section{Talotekniset valinnat}

Rakennus lämpöeristetään tavanomaisia kotieläinrakennuksia paremmin. Eristepaksuuden kasvattaminen ei ole kustannuskysymys varsinkin kun eristemateriaalina käytetään edullista sahanpurua. Parempi eristys kohottaa sisäpintojen lämpötilaa, jolloin kosteuden tiivistyminen rakenteiden pinnoille ei ole niin voimakasta kuin huonommin eristetyillä pinnoilla. Parempi eristys pienentää rakennuksen kokonaislämmitystarvetta. Lämmitykseen käytetään puukattilaa, jolloin energialähteenä on uusiutuva kotimainen polttoaine.

Energiakulutusta pienennetään valitsemalla ilmanvaihtoon painovoimainen toimintaperiaate. Sen toimivuus turvataan korkeilla poistokanavilla. Kesäaikainen toimivuus voidaan varmentaa sähköpuhaltimin. Ilman sisäänotto tapahtuu itkupelti-tuloilmalaitteen kautta, joka talviolosuhteissa hieman esilämmittää tuloilmaa ja samalla tiivistää kosteutta eli kuivattaa sisäilmaa.

\section{Johtopäätökset}

Luomusikalamalli soveltuu sellaisenaan uudisrakennukseksi, mutta toiminnallisen joustavuutensa vuoksi sitä voidaan muunnella osaksi jo olemassa olevia rakennuksia, mikä useasti onkin tilanne nykyisillä sikatiloilla. Rakennuksen ominaisuuksissa toteutuvat elokuussa 2001 voimaan tulleet kotieläintuotannon luomuohjeet selkeästi yli tavoitetason. Tämän lisäksi itse rakennus noudattaa kestävän kehityksen periaatteita; rakennus tuottaa mahdollisimman pienen ympäristökuorman elinkaarensa aikana.

Tämän luomusikalamallin kustannusarvio on $269000 €$. Neliöhinta on hieman alle $240 €$. Rakennuskustannus ei ole tavanomaisiin sikaloihin verrattuna juurikaan korkeampi. Kustannuksia tavanomaisiin sikaloihin nähden kohottavat ulkoilualueiden perustaminen, pinnoitteet, aidat ja jätevesien keräily. Kustannuksia lisäävät myös sikojen ulkoluukut. Kaikki edellä mainitut puuttuvat tavanomaisen tuotannon rakennuksista.

Luomusianlihan kustannuspaineet "tehotuotantoon" verrattuna syntyvätkin eniten eläinten pintaalavaatimuksesta, joka mitoittaa rakennuksen läpi menevän vuosituotannon. Tavanomaisena yhdistelmäsikalana tämä rakennusmalli olisi liian pieni yksikkö taloudellisessa mielessä. Pelkkänä luomuemakkosikalana tämän rakennuksen vuosituotanto on 1080 porsasta ja tavanomaisena emakkosikalana 2680 porsasta. Vastaavasti pelkkänä luomulihasikalana vuosituotanto on 1800 lihasikaa ja tavanomaisena 2700 lihasikaa. Luomuemakkosikalan tuotantoteho lattianeliömetriä kohden on siten vain $40 \%$ ja luomulihasikalana $66 \%$ tavanomaiseen ja saman suuruiseen rakennukseen verrattuna. Vastaavasti tavanomaisen sianlihan tuottajahinta on tällä hetkellä noin $60 \%$ luomusianlihan hintatasosta. Luomusianlihatuotannon suuri kysymys onkin, riittääkö nykyinen korkeampi hintataso yksin houkuttelemaan viljelijöitä investoimaan uusiin luomusikaloihin ja turvaamaan tuotannon määrää pidemmällä aikavälillä. Rakennuskustannuksia tuetaan tasavertaisesti tavanomaisen tuotannon sikalarakennuksiin verrattuna. Tuki on neliömetriperusteinen, joten se kohdentuu luomusikalassa tehottomammin eläinyksikköä kohden. Nähtäväksi jääkin, paikkaako luomustrategiatyöryhmän esittämä luomukotieläintuki tuotantoympäristön suuremmasta väljyydestä aiheutuvaa eläinkohtaisen tuen vajetta.

\section{Kirjallisuus}

Luonnonmukaisen tuotannon ohjeet - eläintuotanto, 2000. Kasvintuotannon tarkastuskeskus, KTTK:n julkaisuja B2 Luomutuotanto, Loimaa. 52 p.

Westermarck, M., Lundsten, B., Heuru, E.-R., 1996. Luonnonmukaisten rakennusaineiden valmistus ja käyttö maatilojen sivuelinkeinona. Teknillisen korkeakoulun arkkitehtiosaston julkaisuja 1996/32.102 p

Maatalousrakennusten suunnitteluohjeet MRO C, 1993. Rakennustieto Oy, Rakennustietokortti MTH-20920, $35 \mathrm{p}$. 